\section{Acharya $\mathrm{K}^{1}$ \\ Pradhan $\mathrm{B}^{1}$ \\ Thapa $\mathbf{N}^{1}$ \\ Khanal S 2}

Ganesh Man Singh Memorial Academy of ENT and Head \& Neck Studies, Institute of Medicine (IOM),

Maharajgunj, Kathmandu, Nepal ${ }^{1}$

Department of Ophthalmology,

TU Teaching Hospital,

Institute of Medicine (IOM),

Maharajgunj, Kathmandu, Nepal ${ }^{2}$

\section{Correspondence to:}

Dr Kunjan Acharya

Lecturer,

Department of ENT-HNS

Ganesh Man Singh Bhawan,

TU Teaching Hospital

Institute of Medicine, Kathmandu, Nepal e-mail: acharyakunjan@hotmail.com

\section{COMPARISON OF OUTCOME FOLLOWING ENDOSCOPIC DACRYOCYSTORHINOSTOMY WITH EXTERNAL DACRYOCYSTORHINOSTOMY.}

\author{
Objective:
}

To compare the outcome between endoscopic and external dacryocystorhinostomy.

Material \& Met hods:

A Retrospective study was conducted in the Department of ENT-HNS and Ophthalmology at Tribhuvan University Teaching Hospital, Kathmandu, Nepal for 2.5 years starting from Aug 2007 to Feb 2010. The endoscopic dacrocystorhinostomy was done under general anesthesia by the ENT faculty. External dacrocystorhinostomy was done by Ophthalmic surgeon under local anaesthesia. After surgery in both groups syringing of lacrimal duct was done twice in 1st, 2nd and 3rd week postoperatively. The outcome of surgery was categories as blocked and patent during the last syringing.

Results:

There were total of 59 dacrocystorhinostomy done in the period of 2.5 years. Among them 27 underwent endoscopic dacrocystorhinostomy (endo DCR) and 32 patients had external dacrocystorhinostomy. There were total 7 failure cases of dacrocystorhinostomy. Out of them 4 were after the endoscopic procedure and 3 were after external dacrocystorhinostomy. When statistical test was applied for the dacrocystorhinostomy by two different techniques, none of the data was found to be statistically significant.

Conclusion:

Endoscopic dacrocystorhinostomy is comparable with external dacrocystorhinostomy regarding its outcome. However, a prospective study with larger sample size and long term follow up is required to observe the advantage of endoscopic dacrocystorhinostomy over external in the future.

Key w o r d s: dacrocystorhinostomy, endoscopic, external dacrocystorhinostomy.

\section{INTRODUCTION:}

Endoscopic dacryocystorhinostomy(DCR) is newer modality of treatment for the chronic dacryocystitis. In the past external DCR was thought to be gold standard method of treatment. There are certain advantages of the endoscopic DCR. There is no external scar. It preserves the lacrimal pump system. Any intranasal pathology that might have caused failure of the first procedure can be addressed, including adhesions, enlarged middle turbinate and septal deviation. More of the lacrimal sac is preserved with the endoscopic procedure. There are also some disadvantages of endoscopic DCR. The main disadvantage is that endoscopic DCR is a fairly new procedure and so long-term results are unknown. No mucosal flaps are created. Mucosal flaps have been found to decrease recurrence rates in the external procedures. A smaller rhinostomy is performed in endoscopic DCR than in the external procedure. It is interesting to note that in a study by Linberg ${ }^{1}$ there was no correlation between the original size of the bony opening and the size of the healed ostium on follow up. Overall, three groups of procedures for chronic dacryocystitis are currently practiced; external DCR, endoscopic DCR with contact laser, and surgical endoscopic DCR without laser. Many factors influence the outcome of these different approaches, but one of the main factors in determining success rate is the level of obstruction in the lacrimal drainage system. This particular study was conducted to compare success rate following endoscopic and external DCR in our setting. The objectives of this study was to compare the outcome between endoscopic and external dacryocystorhinostomy

\section{MATERIAL AND METHODS:}

It was retrospective study conducted in the Department of ENT-HNS and Ophthalmology at Tribhuvan University Teaching Hospital, Kathmandu, Nepal. The duration of the study was 2.5 years starting from Aug 2007 to Feb 2010. Data was reviewed and was documented in the Performa. The Inclusion criteria were all cases of chronic dacryocystitis undergoing surgeries at Ophthalmology and ENT department. The endoscopic DCR was done under general anesthesia by the ENT faculty. Nasal endoscopy prior to the surgery was mandatory. It was followed by dilatation of puncta and probing of the upper and lower canaliculi of the affected side. Then the mucosal flap was raised anterior to uncinate process to expose underlying lacrimal bone and frontal process of maxilla.These bone were nibbled/drilled to indentify the lacrimal sac. The sac was then probed from lower canaliculi, tented and incised. The anterior lip of sac was removed and syringing was done. External DCR was done by by ophthalmic surgeon under local anaesthesia. In both types of surgeries use of the stent during procedure was randomized. After surgery in both groups, syringing of lacrimal duct was done twice in $1^{\text {st }}, 2^{\text {nd }}$ and $3^{\text {rd }}$ week postoperatively. The outcome of surgery was categories into blocked and patent during the last syringing.

\section{RESULTS:}

There were total of 59 DCR done in the period of 2.5 years. Among them 27 underwent endoscopic DCR and 32 patients had external DCR. (Table. 1)

\begin{tabular}{|c|c|c|c|}
\hline & Group A (stent +) & Group B (stent-) & Total \\
\hline Endo DCR & 12 & 15 & 27 \\
\hline External DCR & 17 & 15 & 32 \\
\hline
\end{tabular}

In the both groups number of female patients were more than male as shown in figure. 1

There were total 7 failure cases of DCR. Out of them 4 were after the

Fig. 1: Distribution of gender

\section{SEX DISRIBUTION}

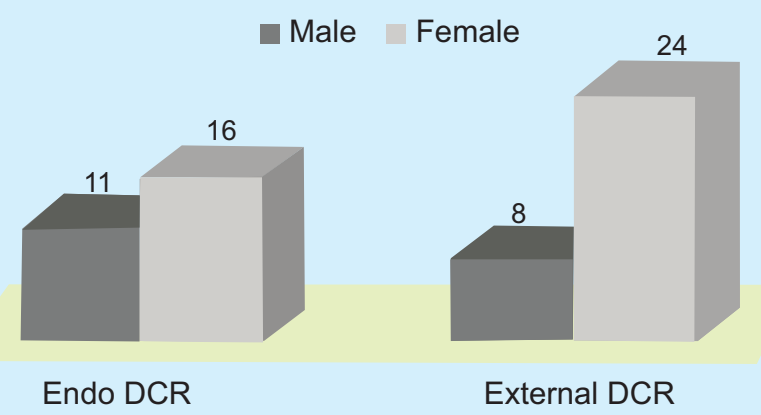


endoscopic procedure and 3 were after external DCR as shown in table 2.

\begin{tabular}{|c|c|c|c|c|}
\hline & \multicolumn{2}{|c|}{ Endo DCR } & \multicolumn{2}{|c|}{ External DCR } \\
\hline & $\begin{array}{l}\text { Group A } \\
\text { (stent +) }\end{array}$ & $\begin{array}{l}\text { Group B } \\
\text { (stent-) }\end{array}$ & $\begin{array}{l}\text { Group A } \\
\text { (stent +) }\end{array}$ & $\begin{array}{c}\text { Group B } \\
\text { (stent-) }\end{array}$ \\
\hline Patent & $9 / 12$ & $14 / 15$ & $16 / 17$ & $13 / 15$ \\
\hline Blocked & $3 / 12$ & $1 / 15$ & $1 / 17$ & $2 / 15$ \\
\hline Failure & \multicolumn{2}{|c|}{$4 / 27$} & \multicolumn{2}{|c|}{$3 / 32$} \\
\hline
\end{tabular}

When statistical test was applied for the DCR done by two different techniques, none of the data was found to be statistically significant as shown in table 3 .

\begin{tabular}{|l|c|c|c|}
\multicolumn{4}{|l}{ Table 3: Analysis of failure cases following endoscopic and external DCR. } \\
\hline & Blocked & Patent & p-value \\
\hline Endo DCR & 4 & 23 & 0.81 \\
\hline External DCR & 3 & 29 & \\
\hline
\end{tabular}

Statistical test: Chi-square with Yates correction

Use of stent in either of the procedure did not make any statistical difference in the outcome of the procedure as shown table 4.

\begin{tabular}{|c|c|c|c|}
\hline & Stent + & Stent - & $\mathrm{p}$-value \\
\hline Endo DCR & 9 & 14 & \multirow{2}{*}{0.38} \\
\hline External DCR & 16 & 13 & \\
\hline
\end{tabular}

Statistical test: Chi-square with Yates correction.

\section{DISCUSSION:}

Since Toti described the initial dacryocystorhinostomy (DCR) operation in 1904 many technical modifications have evolved. ${ }^{2}$ Overall, three groups of procedures are currently practised; External DCR, endoscopic DCR with contact laser, and surgical endoscopic DCR without laser.3,4 In external DCR, Hurwitz and Rutherford reported the operation to be $93 \%$ successful for obstruction at the level of the lacrimal sac or duct. This falls to $73 \%$ in patients with canalicular or common canalicular blockage. There is lot of controversies regarding the gold standard method of treatment for the chronic dacryocystitis. In a study done by Ben et al, in 143 patients, showed that endoscopic DCR (86 cases) had a significantly higher success rate than external DCR (90 cases), $84 \%$ versus $70 \%(P=0.03)$ respectively. ${ }^{6}$ In a prospective, randomised study done by Hartikainen et al 7 , comparing the success rate in 64 patients between endoscopic DCR and external DCR all using stent found that the success rate after 1 year of surgery was $75 \%$ for endoscopic DCR and $91 \%$ for external DCR. This difference however was not statistically significant $(p=0.18)$ Smirnov $^{9}$ conducted a prospective, randomized study to evaluate the necessity of bicanalicular silicone tubes after primary endoscopic DCR in forty-six procedures in 42 patients during 2004-2007. The overall success rate after primary endoscopic DCR was $89 \%$ : with silicone tubes it was
$78 \%$, and without silicone tubes it was $100 \%$. The follow-up period was 6 months and included three follow-up visits: 1 week, 2 months, and 6 months postoperatively. The results showed that the use of silicone tubes after primary endoscopic-DCR is not necessary. The success of the endoscopic DCR ${ }^{8}$ depends upon different factors as mentioned should be taken care. First, stoma made between the bony lateral wall of nose $\&$ medial wall of the sac should be wide enough. Second, the bony edges of the stoma should be smooth.Third, nasal mucosa should be handled with care, to prevent formation of the synechiae \& granulations. Fourth, avoid any postoperative packs, which might occlude the stoma. Fifth, regular follow up with nasal suction \& sac syringing should be done initially to prevent synechiae \& blockage of stoma.

CONCLUSION:

Endoscopic DCR is comparable with external DCR regarding its outcome. There was no significant statistical difference between the two modality of treatment noted in our study. However, a prospective study with larger sample size and long term follow up is required to observe the advantage of endoscopic DCR over external one in the future.

\section{REFERENCES:}

1 Linberg JV, Anderson RL, Bumsted RM, Barreras R. Study of intranasal ostium external dacryocystorhinostomy. Arch Ophthalmol 1982;100:1758-1762.

2 Becker BB. Dacryocystorhinostomy without flaps. Ophthalmic Surg 1988;19:419-27.

3 Woog JJ, Metson R, Puliafito CA. Holmium:YAG endonasal laser dacryocystorhinostomy. Am J Ophthalmol 1993;116:1-10.

4 Jokinen K, Karja J. Endonasal dacryocystorhinostomy. Arch Otolaryngol 1974;100:41-4.

5 Hurwitz JJ, Rutherford S. Computerized survey of lacrimal surgery patients. Ophthalmol 1986;93:14-19.

6. Ben GJ, Joseph J, Lee S, et al. External versus endoscopic dacryocystorhinostomy for acquired nasolacrimal duct obstruction in a tertiary referral center. Ophthalmology. 2005 Aug; 112(8):14638.

7. Hartikainen J, Antila J, Varpula M, et al. Prospective randomized comparison of endonasal endoscopic dacryocystorhinostomy and external dacryocystorhinostomy. Laryngoscope. 1998 Dec;108(12):1861-6.

8. Singhal SK, Bansal S, Dass A et al. Endoscopic Dacryocystorhinostomy Without Stents: Analysis Of 37 Patients. The Internet Journal of Otorhinolaryngology. 2005. 4: 1.

9. Smirnov $G$, Tuomilehto $H$, Teräsvirta $M$ et al. Silicone tubing is not necessary after primary endoscopic dacryocystorhinostomy: a prospective randomized study. American journal of rhinology. 2008; 22(2): 214-7. 